\title{
'Reading' World Link: A Visual Social Semiotic Analysis of an EFL Textbook
}

\author{
Gabriella Torres \\ Assistant Professor, Hankuk University of Foreign Studies \\ 89 Wangsan-ri, Mohyeon-myeon, Choin-gu, Yongin-si, Gyeonggi-do, South Korea \\ Tel: 82-31-330-4030Ｅ-mail: gstorres@gmail.com
}

Received: February 24, 2015 Accepted: March 7, 2015 Published: March 7, 2015

doi:10.5296/ijele.v3i1.7200 URL: http://dx.doi.org/10.5296/ijele.v3i1.7200

\begin{abstract}
As Kress (1993: 174) states, "no sign is innocent" and therefore no text, no matter how innocuous, bland or mundane, should be free from critical reading. This paper sets out to do just this by examining World Link (2011), an EFL textbook used in a South Korean university context, by using a framework of 'visual grammar' established by Kress and van Leeuweun (2006). The paper begins by reviewing the grounding theories of semiotics on which the framework is based. It then uses the framework to perform an analysis of the representational and interactive patterns of two pages from the World Link textbook. The author concludes with a discussion of her findings by addressing the embedded ideologies discovered within the pages and considering how these meaning potentials relate to the purposes of the textbook and thereby the greater purposes of the publisher, Heinle Cengage Learning.
\end{abstract}

Keywords: Discourse analysis, multimodal, social semiotics, Kress and van Leeuwen, visual grammar 


\section{Introduction}

Open up any EFL textbook aimed at university students and, accompanying the text on the page, you are likely to find images of a couple at a restaurant, students chatting on campus or friends taking a trip. Certainly these images serve as a means to illustrate vocabulary words or to represent different types of real-world communication in addition to getting students' interest or attention. However, as Kress (1993: 174) states, "no sign is innocent" and therefore no text, no matter how innocuous, bland or mundane, should be free from critical reading as "all texts equally code the ideological positions of their producers" (Kress 1993: 174).

What then are the ideologies embedded in the images of the EFL textbook? How are they encoded there and, perhaps more importantly, why are they there? This paper aims to answer these questions by using the framework established by Kress and van Leeuwen (2006) to examine how different elements of the image, specifically in regards to subject representation and viewer-participant interaction, work together in the EFL textbook World Link: Developing English Fluency to make meaning potentials and to consider how these meaning potentials relate to the purposes of the textbook and thereby the greater purposes of the publisher Heinle Cengage Learning.

\section{Kress and van Leeuwen: The Grammar of Visual Images}

Methods for the analysis of written texts form a large area of concern in the field of Discourse Analysis. However, more often than not, the texts we encounter in our daily lives make use of more than just one mode of communication. As Lister and Wells observe, "with the late twentieth century's explosion of imaging and visual technologies...everyday life has become 'visual culture'" (Lister and Wells 2001: 61). Advertisements, webpages, textbooks, and phone applications, to name a few examples, all make use of written and visual modes of communication to convey their messages. These are all multimodal texts and although methods of approaching the analysis of the linguistic elements of the text are well established (see Caldas-Coulthard and Coulthard 1996; Fairclough 2003,) a framework is needed which can be used as a tool for visual analysis to examine how visual elements combine to make a meaningful whole (Kress and van Leeuwen 2006).

Kress and van Leeuwen (2006) propose such a framework, which they refer to as the 'grammar' of visual design:

Just as grammars of language combine in clauses, sentences and texts, so our visual 'grammar' will describe the way in which depicted elements - people, place and things - combine in visual 'statements' of greater or lesser complexity. (1)

This framework is an attempt to systematize the regularities in the way image elements are used to make meaning, in other words, to articulate the grammar of visual communication. This can then serve as the basis for an investigation into how visual and verbal messages work together (or in opposition) and the different communicative function each mode fulfills in the multimodal text, a practice that becomes increasingly important as visual 
communication takes on an ever-expanding role in contemporary discourse (Fairclough 1999).

\subsection{Grounding Theories: From Sign to Semiotic Resource}

In order to understand Kress and van Leeuwen's framework it is first necessary to place it within the context of how the 'sign' and semiotic theory have developed, beginning with Ferdinand de Saussure and his work regarding the linguistic sign.

\subsubsection{Saussure and the Linguistic Sign}

According to Saussure, the sign is "the union of a signifier and a signified...or else of an acoustic image and a concept" (Barthes 1973: 38) In other words, the signifier is a sequence of sounds while the signified is the abstract mental concept associated with that particular sound sequence making the word itself the sign. This could be visually represented as the following:

\begin{tabular}{|l|l|}
\hline Signifier (sound) & \multirow{2}{*}{ Sign (word) } \\
\hline Signified (concept) & \\
\hline
\end{tabular}

Figure 1. Saussure's Linguistic Sign

For Saussure, the relation between signifier and signified is "arbitrary and exact" (Barthes 1973: 38) with no inherent link existing between the two. The relation is purely a matter of social convention, a relation that he describes as the arbitrariness of the sign.

\subsubsection{Barthian Semiotics and the Semiological Sign}

Coming out of the Paris School of the 1960's and 1970's, where the ideas of Saussure and other linguists were applied to non-linguistic texts, is Barthes's visual semiotics. Like Saussure's linguistic sign, Barthes's visual semiological sign "is also...compounded of a signifier [image] and a signified [concept]” (Barthes 1973: 41). However, in Barthes's visual semiotic model this only represents the first layer of meaning, the denotation, or, more specifically, the 'who' or 'what' that is depicted in the image (van Leeuwen 2001). A second layer of meaning is superimposed onto the sign which Barthes calls the connotation. This "second-order semiological system" (Barthes 1972: 113) encompasses the layer of "broader concepts, ideas and values, which the represented people, places and things [denotation] 'stand for', 'are signs of'" (van Leeuwen 2001: 96) and which come about through the cultural associates which "cling to them" (van Leeuwen 2001: 97). In Mythologies (1972), Barthes refers to these connotative meanings as 'myths' because of their power to 'naturalize' ideologies or the status quo and the interests of those whose power is invested in them (van Leeuwen 2001). 


\subsubsection{Halliday and the Semiotic Resource}

Greatly influencing the work of Kress and van Leeuwen is Halliday's (1978) social semiotic view of language. According to Halliday, language is a product of the social process, which consists of "the exchange of meanings in interpersonal contexts of one kind or another" (1978: 2 ). In this sense, language is a system of semiotic resources (resources for making meaning) that, as per Halliday (1978), simultaneously perform the following three meta-functions:

1) The ideational function represents the speaker's meaning potential as an observer. It is the content function of language, language as 'about something' [i.e. to describe the world around us and within us]. (112)

2) The interpersonal function represents the speaker's meaning potential as an intruder. It is the participatory function of language, language as doing something. It expresses role relationships associated with the situation. (112)

3) The textual function represents the speaker's text-forming potential. It expresses the relation of the language to its environment. It is only in combination with textual meanings that ideational and interpersonal meanings are actualized. (113)

\subsection{Kress and van Leeuwen: Reading Images}

Building from these theories, Kress and van Leeuwen have developed a systematic method for 'reading' or describing the 'grammar' of visual images or the way in which image elements are combined into meaningful wholes. Expanding Halliday's social semiotic view of language to encompass the mode of visual communication, Kress and van Leeuwen (2006) propose all images fulfill Halliday's three major functions (see section 2.1.3) through the following patterns:

1) Patterns of representation: These correspond to Halliday's 'ideational' meta-function and refer to the visual resources for the representation of interactions and conceptual relations between the people, places and things depicted in the image.

2) Patterns of interaction: These correspond to Halliday's 'interpersonal' meta-function and refer to the resources, which construct relationships between the viewer, the image producer and the people represented in the image.

3) Patterns of composition: These correspond to Halliday's 'textual' meta-function and refer to ways in which patterns of representation and interaction cohere into meaningful wholes.

Like Barthes before them, Kress and van Leeuwen (2006) see images as the means for the articulation of ideological positions as, according to the authors, "neither power nor its uses has disappeared. It has only become more difficult to locate and trace" (14). It is their hope that this framework provides the basis from which we can begin to uncover what ideologies or 'interests' lurk behind the text.

\section{3. 'Reading' World Link: A Visual Social Semiotic Analysis}

The following section of this paper will use Kress and van Leeuwen's framework to analyze 
images from two pages (see Appendix) of World Link: Developing English Fluency (2011), a set EFL textbook for students of Practical English, a required course at Hankuk University of Foreign Studies in South Korea. Both pages (Figure 2 and Figure 3) from the textbook are designed to look like 'webpages' and are classified as such. Each page depicts two 'webpages', which are comprised of written text and an image. For this analysis, the author will refer to the images as 'top webpage' (TWP) or 'bottom webpage' (BWP). For Figure 3, the author will refer to the images on the BWP as left (LBWP) or right (RBWP). For the purposes of this paper, this analysis will focus on 1) the ways in which the people in the image are represented (Representational Patterns) and 2) the kinds of relationships that are suggested to exist between the viewer and the represented participants (Interactive Patterns).

\subsection{Representation}

Representation refers to not only the represented participants (people, places and things) depicted in the image but to how these participants relate to one another in meaningful ways. Kress and van Leeuwen (2006) identify two patterns or processes of representing this relation: narrative and conceptual.

\subsubsection{Narrative Patterns}

The distinguishing feature of a narrative pattern is the presence of a vector. A vector is an oblique line formed by arrows, bodies, limbs or tools, which connects participants and expresses unfolding actions or events. Participants in narrative patterns are labeled as 'Actor', the participant from whom the vector emanates, and 'Goal', the participant at whom the vector is directed (Kress and van Leeuwen 2006). This is also called a transactional process.

The images in Figure 2 both use transactional processes in their representation. In the TWP image we see the 'father' as the Major Actor whose arms create a vector connecting him with his 'family' thus making the 'son', 'wife' and 'daughter' Goals. The image could be transcoded as, "The father embraces his family". In the BWP image there are a variety of transactional processes represented: in the foreground, Major Actor (Old Man) arranges his produce (Goal); Major Actor (Woman in Blue Shirt) inspects peppers (Goal). In the background, Major Actor (Woman in White Hijab) reaches for some eggs (Goal).

\subsubsection{Conceptual Patterns}

In conceptual patterns, the vector is absent. Instead, participants are represented as static or as their generalized essences in terms of class, structure or meaning. These conceptual relations are realized through three sub-processes: classification, analytical and symbolic processes (Kress and van Leeuwen 2006).

Classification processes "bring different people, places or things together in one picture, distributing them symmetrically across the picture space to show that they belong to the same class" (Jewitt and Oyama 2001: 144). Kress and van Leeuwen (2006) refer to this as a "kind of' relation. Analytical processes relate participants in terms of a part-whole structure, in which a concept or entity is defined by showing how it is made up out of which parts. This process involves two kinds of participants: one Carrier (the whole) and any number of 
Possessive Attributes (the parts). Finally, symbolic attributive processes define the meaning or identity of a participant (Carrier) through the participant that represents the meaning or identity itself (Symbolic Attribute).

In Figure 3, the TWP image and BLWP image both use analytical processes of representation. In the TWP image the represented participants (Tetsuya and his friends) are Carriers in relation to their Possessive Attributes (uniforms, backpacks, glasses), which create visual concepts of their 'Japaneseness' and/or 'Schoolboyness' (Kress and van Leeuwen 2006: Ch. 3). In contrast, in the LBWP image the represented participant (a now grown up Tetsuya, or Ted) is a Carrier of 'Americanization' in relation to his Possessive Attributes (baggy jeans, hooded sweatshirt, oversized hooded jacket with bright yellow lining, sneakers and skateboard), which create visual concepts of his 'Americanness'. Furthermore, this image can also be said to use a symbolic attributive process. As Kress and van Leeuwen (2006) point out:

Human participants in Symbolic Attributive processes usually pose for the viewer, rather than being shown as involved in some action...they take up a posture which cannot be interpreted as narrative: they just sit or stand there, for no reason other than to display themselves to the viewer. (105-106)

In the LBWP image, Ted is in such a pose. In this process, he is the Carrier of 'Americanness' and his American identity is established by means of his symbolic attribute, the skateboard.

\subsection{Interaction}

According to the framework, images involve two kinds of participants, represented participants (see section 3.1) and interactive participants, or the people who communicate to each other through the images; in other words, the image-maker and the image-viewer. Between these participants, relations are represented thus suggesting the attitude viewers should take towards what is being represented. As per Kress and van Leeuwen (2006), the semiotic resources relating to gaze, social distance, horizontal angles and vertical angles are the means through which these relations are communicated.

\subsubsection{Gaze}

Some pictures show people looking directly at the viewer while others do not. Following Halliday (1985), Kress and van Leeuwen (2006) refer to images in which the participants make 'eye contact' with the viewer as 'demand' images in that by directly 'addressing' the viewer, the represented participants symbolically 'demand' something from the interactive participant, that the viewer enter into some kind of imaginary relation with them, for example. By contrast, other images address the viewer indirectly. In these pictures, the participants do not make eye contact and, instead, they become the object of the viewer's gaze. Again, following Halliday (1985), Kress and van Leeuwen (2006) call this kind of image an 'offer': the participants are 'offered' to the viewer "as items of information, objects of contemplation, impersonally, as though they were specimens in a display case" (119).

The TWP images in Figure 2 and 3 are both 'demand' images in which the represented 
participants look directly at the viewer. According to Kress and van Leeuwen (2006), what the participant is 'demanding' is signified by other means, such as their facial expressions and gestures. In Figure 2's TWP image, the family smiles at the viewer, which could be seen as an invitation to enter into a relation of social affinity with them. Similarly, the schoolboys in the TWP image of Figure 3 also smile at the viewer, again inviting the viewer to enter into a relation of playful, social affinity.

In contrast to the 'demand' images described above, the BWP images in Figures 2 and 3 are 'offer' pictures, where the represented participants are offered to the viewer for detached observation. Beginning with Figure 2, the BWP photograph depicts a busy street of, according to the accompanying text, Fes-al-Bali, a neighborhood in Fes, Morocco. We examine the participants in their daily life, observing them like a tourist. As Lister and Wells (2001) state:

[W]e look at images of people who appear unaware of the presence of the camera and - by extension - the possibility of becoming the object of someone else's look.... This notion of the voyeuristic gaze has been used to describe the way in which tourists look at the non-Western world. (84)

It could be argued that the young boy in the foreground looks at the camera thus rendering the image a 'demand' picture rather than an that of an 'offer'. However, as Kress and van Leeuwen observe in their analysis of the representation of Aboriginal people in Australian textbooks:

[E]ven if they do, occasionally, look directly at the viewer, they do so from a long distance, which greatly diminishes the impact of their look, or are figures in the background, looking blankly and more or less accidently in the direction of the camera. (2006: 119-120)

The gaze of the boy in this image seems more accidental than intentional, and though the viewer is 'caught in the act' of viewing, this does not diminish our position as the invisible onlooker.

The BWP images in Figure 3 are also 'offer' images: in both instances the gaze of the participant is directed away from the viewer. In these pictures we see Ted (no longer Tetsuya as indicated by the accompanying text) in his new home, Los Angeles, skateboarding by himself in front of an industrial looking building. The images invite us to observe Ted, though not to identify with him. This makes for an interesting comparison with the 'demand' image of the TWP image above, where Tetsuya is pictured as a schoolboy in Japan and we are invited to relate to him in a friendly and playful way.

\subsubsection{Social Distance}

Just as images can depict a 'demand' or an 'offer' relation based on the direction of the represented participant's gaze, so can they depict social relations based on represented distances between the participant and the viewer. As Kress and van Leeuwen note, "In everyday interaction, social relations determine the distance (literally and figuratively) we 
keep from one another" (2006: 124). These social distances are translated to the image by choices in size of frame. To help classify these distances, Kress and van Leeuwen (2006) adopt a scheme from Edward Hall (1966) and borrow from the language of film and television. The classification of Social Distance is represented in Table 1 below.

Table 1. Framing and Social Distance

\begin{tabular}{|c|c|c|}
\hline $\begin{array}{c}\text { Hall's Social Distance } \\
(1966: 110-120)\end{array}$ & $\begin{array}{c}\text { Field of Vision } \\
\text { Kress and van Leeuwen (2006: } \\
125)\end{array}$ & $\begin{array}{c}\text { Size of Frame } \\
\text { Kress and van Leeuwen } \\
(2006: 124)\end{array}$ \\
\hline 'Intimate distance' & Face or head only & Very close shot \\
\hline 'Close personal distance' & Head and shoulders & Close shot \\
\hline 'Far personal distance' & Waist up & Medium close shot \\
\hline 'Close social distance' & Whole figure & Medium long shot \\
\hline 'Far social distance' & Whole figure with space around it & Long shot \\
\hline 'Public distance' & Torso of at least 4-5 people & Very long shot \\
\hline
\end{tabular}

Table 2 outlines the representations of social distances in the images of Figures 2 and 3.

Table 2. Social Distance in Figures 2 and 3

\begin{tabular}{|c|l|l|}
\hline Figure & $\begin{array}{l}\text { Image } \\
\text { Location }\end{array}$ & Social Distance \\
\hline 2 Appendix) & TWP & $\begin{array}{l}\text { Close social distance: We see almost the whole figure of the participants with } \\
\text { space around them. As per Hall, "People who work together tend to use close } \\
\text { social distance. It is also a very common distance for people who are attending } \\
\text { a casual social gathering" (1966: 121). }\end{array}$ \\
\cline { 2 - 4 } Appendix) & BWP & $\begin{array}{l}\text { Public distance: We can see the torso of at least four to people. This is the } \\
\text { distance for "people who are to remain strangers" (Hall 1966: 125). }\end{array}$ \\
\cline { 2 - 4 } & BWP & $\begin{array}{l}\text { LBWP } \\
\text { Close social distance: We see the whole figure of the participant. This is the } \\
\text { distance in which "impersonal business occurs" (Hall 1966: 121). See also the } \\
\text { Social Distance description for TWP from Figure 2. }\end{array}$ \\
\cline { 2 - 4 } & $\begin{array}{l}\text { RBWP } \\
\text { Far social distance: We see the whole figure of the participant with some } \\
\text { space around it. This is the distance in which "business and social discourse } \\
\text { is conducted... [it] has a more formal character" (Hall 1966: 122). }\end{array}$ \\
\hline
\end{tabular}

What is notable from looking at Table 2 is that only one image represents the viewer and the participants as strangers, the BWP image in Figure 2 depicting Fes-al-Bali. Here, we see torsos of numerous participants who are represented from the public space of the urban street. At this distance, they are no longer represented as individuals; they are shown "impersonally, as strangers with whom we do not need to become acquaintances, as 'trees in a landscape'" 
(Kress and van Leeuwen 2006: 126). This representation of social distance, and thereby social relation, stands in great contrast to the images depicting scenes from New York, Japan and Los Angeles in which we, the viewers, inhabit the personal and social realms where interaction is more likely to take place.

\subsubsection{Horizontal Angle}

Another means for representing symbolic social relations between the viewer and represented participants is the horizontal angle. The horizontal angle is a function of the relationship between the frontal plane of the interactive participants and the frontal plane of the represented participants: the two can either be aligned with one another or diverge from one another forming an oblique angle (Kress and van Leeuwen 2006). According to the parameters of the framework, the difference between the oblique and frontal angle is the difference between the feelings of involvement or detachment the viewer has toward the people in the image. Kress and van Leeuwen (2006) explain it in the following terms:

The frontal angle says, as it were, 'What you see here is part of our world, something we are involved with.' The oblique angle says, 'What you see here is not part of our world; it is their world, something we are not involved with'. (136)

In other words, the frontal angle represents maximum involvement: the viewer is directly confronted with what is in the picture. Depicted from an oblique angle, the viewer literally and figuratively remains on the sidelines; they are detached from who or what they see. Table 3 shows the various uses of the horizontal angle in Figures 2 and 3.

Table 3. The Horizontal Angle in Figures 2 and 3

\begin{tabular}{|r|l|l|}
\hline Figure & $\begin{array}{l}\text { Image } \\
\text { Location }\end{array}$ & The Horizontal Angle \\
\hline Appendix $)$ & \multirow{2}{*}{$\begin{aligned} \text { TWP } \\
\text { (see }\end{aligned}$} & $\begin{array}{l}\text { Frontal angle: we are maximally involved with the participants. We are aligned } \\
\text { with them. What we see here is 'part of our world'. }\end{array}$ \\
\cline { 2 - 4 } & BWP & $\begin{array}{l}\text { Oblique angle: the frontal plane of the participants forms a 90-degree angle } \\
\text { with the frontal plane of the viewer. We are detached from the participants and } \\
\text { view them 'from the sidelines'. What we see here is not 'part of our world'. }\end{array}$ \\
\hline & BWP & $\begin{array}{l}\text { Frontal angle: we are maximally involved with the participants. We are aligned } \\
\text { with them. Again, this is a 'part of our world'. }\end{array}$ \\
& $\begin{array}{l}\text { LBWP } \\
\text { Slightly oblique angle: we are not maximally involved with the participant } \\
\text { however we are not fully detached. The participant is shown as like 'us', the EFL } \\
\text { university students for whom the textbook is intended (Kress and van Leeuwen } \\
\text { 2006). }\end{array}$ \\
\hline & $\begin{array}{l}\text { RBWP } \\
\text { Slightly oblique angle: again we are not fully involved with the participant } \\
\text { though not completely detached either. The participant is once again shown as }\end{array}$ \\
\hline
\end{tabular}




\begin{tabular}{|l|l|l|}
\hline & $\begin{array}{l}\text { like 'us', the EFL university students for whom the textbook is intended (Kress } \\
\text { and van Leeuwen 2006). }\end{array}$ \\
\hline
\end{tabular}

Again, as with Table 2 in Section 3.2.2, what is notable is that only one picture is photographed from a distinctly oblique angle, the picture of Fes-al-Bali. As noted in Table 3, the frontal plane of the participants in this image forms a 90-degree angle with the frontal plane of the viewer, thus we observe them in a detached manner from the sidelines. Not only, then, are the people in the Fes-al-Bali image 'offered' to us like "specimens in a display case" (see 3.2.1), the long shot keeps them at a pubic distance where they are to remain strangers (see 3.2.2) while the oblique angle reinforces these positions by saying, "What you see here is not part of our world; it is their world, something we are not involved with" " (Kress and van Leeuwen 2006: 136).

\subsubsection{Vertical Angle}

The final visual resource in the framework used to represent interactive relations between viewer and participant is that of the vertical angle. According to the framework, if a person is seen from a high angle, then the viewer has symbolic power over the represented participant. If the represented participant is seen from a low angle, then it is the represented participant who has symbolic power over the viewer. Finally, if the participant is at eye-level, then there is a relation of symbolic equality and there is no power difference involved (Kress and van Leeuwen 2006).

Let us analyze the vertical angles in Figure 2. In the TWP image, the photograph is taken slightly above eye-level, thus the Inwood family is represented as having some slight symbolic power over the viewer. In the BWP image, the power relations are quite different. Here the viewer sees the participants from a high angle, placing the viewer in a position of symbolic power over the residents of Fes-al-Bali. Not only are they represented as strangers (see Section 3.2.2) whom we view detachedly from the sidelines (see section 3.2.3) and observe as if we were tourists (see Section 3.2.1), but we do so from a position of power.

In Figure 3, the TWP image is at eye-level creating a relation of symbolic equality between the viewer and Tetsuya and his friends. In the BWP images, however, the relation changes. In both BWP photographs, Ted is seen from a low angle, thus placing him in a symbolic position of power over the viewer. This is an interesting juxtaposition for the image-producer to make and can be read as the following: while in Japan, we are equals with Tetsuya, however following his move to Los Angeles and subsequent "Americanization", the balance shifts. Ted, with his improved English speaking ability, as indicated by the accompanying text, is more powerful than the intended viewer, the EFL student in Asia. It is not too far of a stretch to perceive a link with English ability and positions of power. This idea will be discussed in more detail in Section 4.3 below.

\section{Discussion}

Having completed the visual analysis of Figures 2 and 3, the writer will now attempt to relate the findings to the purposes of the textbook and the publishing company Heinle Cengage 
Learning.

\subsection{Texts in Contradiction}

As Jewitt and Oyama point out, "images play a role that goes far beyond the mere illustration of what is communicated in language, and images can contradict and work against spoken or written messages" (2001: 138). This is quite evident in the written text of the BWP in Figure 2. In this text we see Farid's description of his neighborhood, Fes-al-Bali, as a post on his webpage. This first-person account is friendly, cheerful and inviting. The accompanying image, however, seems to contradict the written message. Though the web post invites the reader into a relation of social affinity with the writer, the associated image communicates something different: the relation between the viewer and participants is that of strangers. In the visual image Farid loses the "I-ness" he had in his web post; he is depicted from a long distance as to render him a stranger. Farid joins his neighbors in their 'otherness' and we observe them in their daily urban life from a detached position of power.

We find another instance of this type of contradiction in the BWP of Figure 3. The text is another post on a webpage. This time Ted cheerfully describes his new life in Los Angeles. According to the post, Ted has many friends with whom he speaks English. However, once again, the image signals something different. In the BWP images of Ted he appears alone and aloof; he does not make eye contact with the viewer and instead 'offers' himself for observation from his perch of symbolic power (see Section 3.2.3). We observe him with interest, but he no longer returns our gaze or observes us with interest (Berger 1972: 133). To borrow Berger's (1972) terminology, Ted has become 'glamorous' via his Americanization; he becomes, in a sense, an advertisement for this change.

\subsection{Fairclough's Questions}

What, then, can we take these contradictions to mean? Or, in Fairclough's (1999) terms, "whose representations [and contradictions] are these [and] who gains what from them?" (150). The first of Fariclough's questions has a two-tiered response. First and foremost, these representations belong to image banks such as Getty, Shutterstock and Alamy, from where the publishing company purchased them. Once purchased by Heinle Cengage Learning, the images are appropriated to the context of the World Link textbook, where the representations, to varying degrees, work in tandem with the written text to meet the needs of the publishing company.

We are now in a position to address Fairclough's second question with respect to who gains what from these representations? Heinle Cengage Learning is an American educational publishing company with annual revenues of approximately two billion dollars and 5,500 employees in offices and operations in more than twenty countries around the world (Cengage Learning 2010). ELT forms a significant division of the company, with customer bases throughout Asia, Australia, South America, Mexico, Europe and the Middle East, thus making ELT a large earner for the publisher. Therefore, what Heinle stands to gain from these representations is significant. English Language Teaching is, in fact, big business making the English language itself, "marketable and sort of a commodity" (Cameron 2000; Heller 2003 
cited in Jaworski and Coupland 2006: 5). This is a commodity that, like many commodities, is marketed via branding. As Machin notes (2004), we are in an age of branding where product ranges are associated with "the moral values of the new capitalism...so that companies no longer sell whiskey but friendship, no longer shampoo but hope, and so on" (331).

\subsection{English as Power}

What then are the moral values of the new capitalism? Machin (2004) sites togetherness, friendship, protection, globalization and freedom amongst others, all of which are present to some degree in four out of the five images that were analyzed in Section 3. The family (Figure 2, TWP) from Inwood depicts togetherness and protection; Tetsuya (Figure 3, TWP) and his schoolmates embody friendship while Ted (Figure 3, BWP) represents globalization, freedom and independence. English language, as per World Link, is a means of realizing these values. Through English, one can achieve togetherness and freedom; one can become a member of the global community.

However, it should be noted, that through English one can also achieve power, a value, or promise, that is embedded in the World Link textbook. The visual analysis of Figures 2 and 3 has demonstrated how English speakers (in America) are depicted as symbolically more powerful through the visual resource of the vertical angle. English speakers are shown from a low angle; non-English speakers are not: they are seen eye-level at best or from a high angle at worst. These representations serve to position the English language, and those who speak it, in a place of power over those who do not. It also instills a sense of fear in the student: if you do not speak English, you will be seen as distant, 'other', powerless and isolated from the global community. These values and fears thus 'naturalize' the need and desire for ELT which increases the demand for EFL classes and thereby EFL textbooks. As Jaworski and Coupland state, "[language's] purveyors can market themselves through their use of linguistic and textual manipulation" (2006: 5). Heinle Cengage Learning do just this and the textbook consequently becomes an advertisement for their brand of English and its promise of power and success.

\section{Conclusion}

In conclusion, Kress and van Leeuwen's framework proved a useful descriptive tool for analyzing the manner in which elements of images from the World Link EFL textbook worked together to produce meaning. Through this analysis, the author was able to pinpoint instances where the visual message was in contradiction with the verbal message and to examine how these contradictions may possibly serve to reveal the ideologies embedded therein. The author then considered how these articulations of value relate to the purposes of the textbook and its publishing company, Heinle Cengage Learning.

This paper opened with Kress's observation that "no sign is innocent"; people are increasingly shaped by the signs they encounter in all aspects of their daily lives. Therefore, it is becoming ever more important to have a means with which to discuss and describe these representations to better understand them and their intentions. I agree with Fairclough who 
states that, "people need from education a range of resources for living within socially and culturally diverse societies and avoiding their dangers including chauvinism and racism" (1999: 151). Kress and van Leeuwen, through their grammar of visual design, provide such a resource.

\section{Acknowledgment}

This work was supported by the Hankuk University of Foreign Studies Research Fund of 2015.

\section{References}

Barthes, R. (1972). Mythologies. New York: Noonday Press.

Barthes, R. (1973). Elements of Semiology. New York: Hill and Wang.

Berger, J. (1972) Ways of Seeing. London: Penguin.

Cengage Learning. (2010). Overview. Retrieved from http://www.cengage.com/about/ (July $28,2012$.

Fairclough, N. (1999). Global capitalism and critical awareness of language. In A. Jaworski \& N. Coupland (eds.) (2006). The Discourse Reader (pp. 146-157). 2nd ed. London: Routledge.

Hall, E. (1966). The Hidden Dimension. New York: Doubleday.

Halliday, M.A.K. (1978) Language as a Social Semiotic. London: Edward Arnold.

Jaworski, A., \& Coupland, N. (eds.) (2006). Introduction. The Discourse Reader (pp. 1-37). 2nd ed. London: Routledge.

Jewit, C., \& Oyama, R. (2001). Visual meaning: a social semiotic approach. In T. van Leeuwen \& C. Jewitt (eds.) (2001) Handbook of Visual Analysis (pp. 134-156). London: Sage.

Kress, G. (1993). Against arbitrariness: the social function of the sign as a foundational issue in critical discourse analysis. Discourse \& Society, 4(2), 169-191. http://dx.doi.org/10.1177/0957926593004002003

Kress, G., \& T. van Leeuwen. (2006). Reading Images: The Grammar of Visual Design. $2^{\text {nd }}$ ed. London: Routledge.

Lister, M., \& Wells, L. (2001) Seeing beyond belief: Cultural studies as an approach to analyzing the visual. In T. van Leeuwen \& C. Jewitt (eds.) (2001). Handbook of Visual Analysis (61-91). London: Sage.

Machin, D. (2004). Visual language: The increasing Global Importance of Image Banks in Corporate Media. Visual Communication, 3, 316-336. http://dx.doi.org/10.1177/1470357204045785 
Stempleski, S., Douglas, N., \& Morgan, J. R. (2011). World Link: Developing English Fluency (pp.53, 118). $2^{\text {nd }}$ ed. Boston: Heinle Cengage Learning.

Van Leeuwen, T. (2001). Semiotics and iconography. In T. van Leeuwen \& C. Jewitt (eds.) (2001) Handbook of Visual Analysis (pp. 92-118). London: Sage.

Van Leeuwen, T., \& Jewitt, C. (eds.) (2001). Handbook of Visual Analysis. London: Sage.

\section{Appendix}

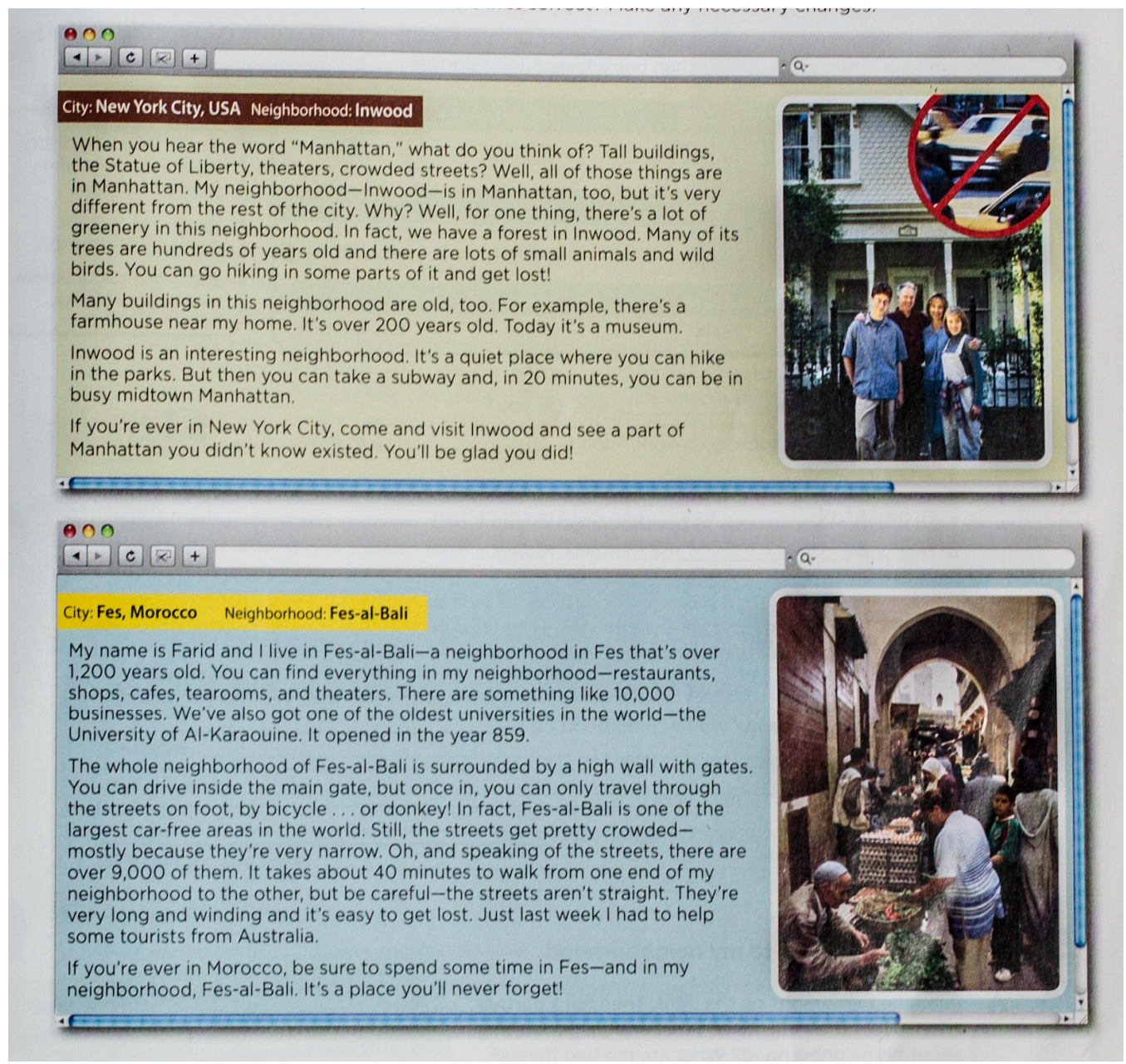

Figure 2. World Link: Developing English Fluency (2011), page 53 


\section{Communication Things have changed.}

A Two years ago, Tetsuya and his family moved from Tokyo to Los Angeles. Look at his old Tokyo web page and his new Los Angeles web page. How has his life changed? Make sentences with used to and didn't use to.
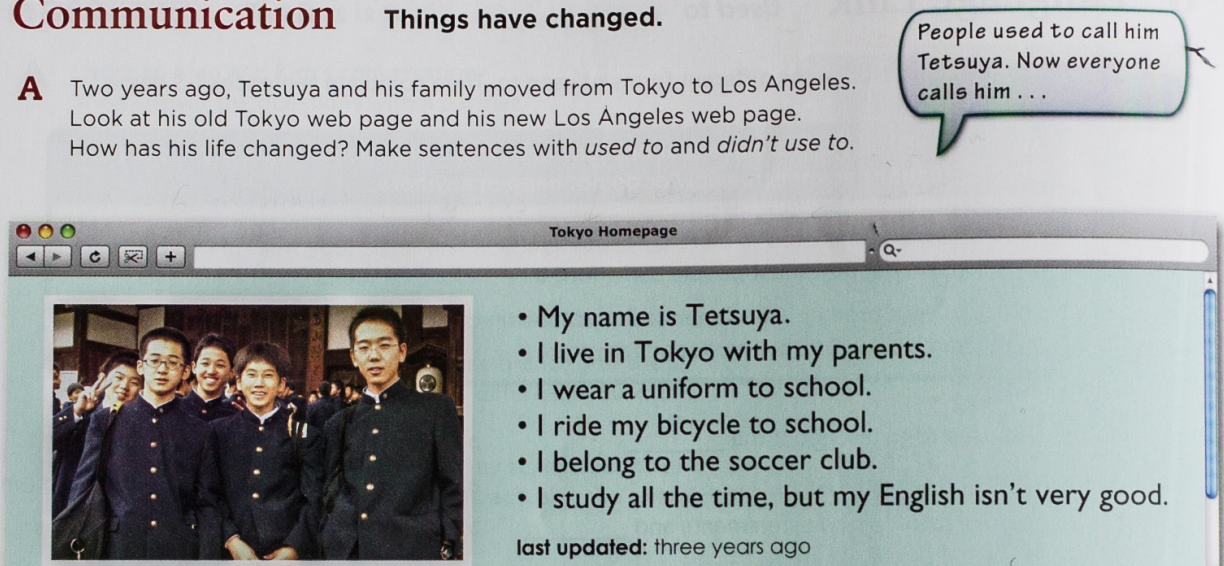
Tokyo Homepage

\section{Q.}

- My name is Tetsuya.

- I live in Tokyo with my parents.

- I wear a uniform to school.

- I ride my bicycle to school.

- I belong to the soccer club.

- I study all the time, but my English isn't very good.

last updated: three years ago

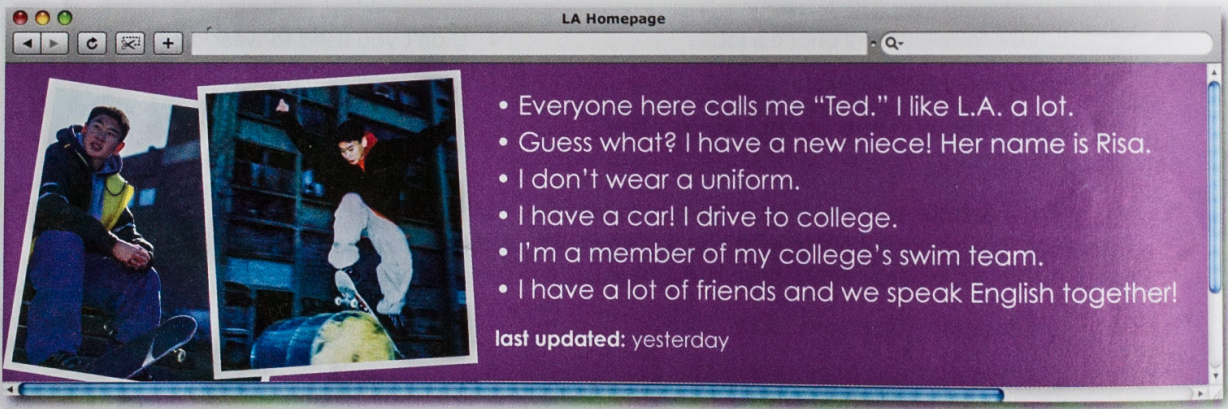

Figure 3. World Link: Developing English Fluency (2011), page 118

\section{Copyright Disclaimer}

Copyright for this article is retained by the author(s), with first publication rights granted to the journal.

This is an open-access article distributed under the terms and conditions of the Creative Commons Attribution license (http://creativecommons.org/licenses/by/3.0/). 